\title{
LA INCONSISTENTE Y BANAL LEY DE GARANTÍA DE LA AUTONOMÍA MUNICIPAL DE EXTREMADURA*
}

\section{THE INCONSISTENT AND BANAL LAW OF GUARANTEE OF THE MUNICIPAL AUTONOMY OF EXTREMADURA}

Clemente JuAN CHECA GONZÁlEZ Universidad de Extremadura

Recibido: 21/o6/2019 Aceptado: 18/09/2019

\section{RESUMEN}

Se critica en este trabajo el contenido de la ley promulgada por la Asamblea de Extremadura en garantía de la autonomía municipal, señalando que en ella se omite, indebidamente, cualquier referencia a la ley estatal, que es a la que corresponde la defensa de dicha autonomía.

Palabras clave: Ayuntamientos, autonomía municipal, financiación municipal.

\section{ABSTRACT}

The content of the law promulgated by the Assembly of Extremadura as a guarantee of municipal autonomy is criticized in this paper, stating that it omits, unduly, any reference to the state law, which is to which the defense of said autonomy corresponds.

Keywords: City Councils, municipal autonomy, municipal financing.

\footnotetext{
* Conferencia impartida en la Facultad de Derecho de la Universidad de Extremadura el 2 de mayo de 2019.
} 
Sumario: 1. Introducción. 2. Acerca del voluntario apartamiento de las bases estatales reguladoras del régimen local en la Ley 3/2019. 3. Las vagas y etéreas normas sobre financiación local recogidas en la Ley 3/2019. 4. A modo de conclusión

\section{INTRODUCCIÓN}

En un intento de elaborar una clasificación de productos normativos que, amparándose en la figura de la ley, pero sin tener el verdadero contenido y alcance predicables de la misma, se puede hablar, entre otros subproductos, de "Leyes manifiesto", aprobadas, como han indicado Muñoz Machado y Fernández Rodríguez, más para hacer una declaración política, o para cubrir la apariencia de que se ha cumplido algún aspecto de un programa político, que para contener mandatos que deban ser hechos efectivos; de "Leyes propósito", destinadas más a aparentar que los ejecutivos se preocupan de un problema concreto que a adoptar soluciones solventes y eficaces sobre el mismo, como ha denunciado Cano Bueso, y de "Leyes oropel, celofán o tribunicias", que están plagadas de bellas intenciones y principios irreprochables, pero carentes de garantías e instrumentos eficaces para su cumplimiento en un plazo cercano, como ha escrito Martín Moreno.

Es difícil que todas estas categorías se encuentren reunidas en una sola ley; pero no imposible, y buena muestra de ello es la Ley 3/2019, de 2 de enero, de normas reguladoras de garantía de la autonomía municipal de Extremadura, que es una ley banal, inconsistente y perfectamente prescindible, hasta el punto de que lo mejor y más oportuno habría sido, desde luego, que jamás se hubiese promulgado. 
2. ACERCA DEL VOLUNTARIO APARTAMIENTO DE LAS BASES ESTATALES REGULADORAS DEL RÉGIMEN LOCAL EN LA LEY 3/2019

En el Preámbulo de dicha Ley 3/2019 -y recalco lo de Preámbulo, pese a que en esta norma se utiliza la denominación de Exposición de Motivos, lo que es una palmaria incorreción jurídica, por los bien expuestos argumentos de Tajadura Tejada - se dedica un amplio apartado a poner de relieve como tras la aprobación de la Ley 27/2013, de 27 de diciembre, de Racionalización y Sostenibilidad de la Administración Local, por la que se modificó la Ley 7/1985, de 2 de abril, reguladora de las Bases del Régimen Local (LRBRL), se plantearon una cascada de impugnaciones ante el Tribunal Constitucional (TC) por medio de la presentación de varios recursos de inconstitucionalidad y un conflicto en defensa de la autonomía local, resueltos por diversas sentencias que comienzan por la pionera 41/2016, de 3 de marzo, a la que han seguido las sentencias 111/2016, 168/2016, 180/2016, 44/2017, 45/2017, 54/2017, 93/2017, 101/2017 y 107/2007, resolutoria de citado conflicto en defensa de la autonomía local planteado por 2.393 municipios.

Hasta aquí todo cierto. Así, efectivamente, ha ocurrido.

Ahora bien, extraer de ello la conclusión, como en dicho Preámbulo de la Ley 3/2019 graciosamente se hace, de que los pronunciamientos de citadas sentencias han atacado frontalmente a la LRBRL hasta el punto de quedarla reducida prácticamente a escombros, es una falsedad completa.

Y lo es porque si bien dichas sentencias del TC sí han declarados inconstitucionales ciertos preceptos de la LRBRL que habían sido modificados o introducidos por la Ley 27/2013, y en otros casos han declarado la constitucionalidad de algunos siempre que se interpretasen de una determinada manera, debe de señalarse, de forma inmediata, que las declaraciones del TC afectan tan solo a cuestiones menores de la LRBRL, no incidiendo para nada en su núcleo esencial, que es el que define las 
competencias propias de los municipios y las delegadas a éstos. Tan es así que si se analizan los arts. 25 a 27 de dicha LRBRL nos encontramos con que los mismos han permanecido indemnes a los embates del TC.

Y sólo una cuestión de escaso calado fue rechazada por la ya antes citada STC 111/2016, cual es la que se contenía en el apartado 2 del art. 26 de la LRBRL, referida a que es la Diputación, en los municipios de menos de 20.000 habitantes, la que tiene que coordinar la prestación de una serie de servicios municipales, punto en el que se declaró inconstitucional y nulo que la Diputación tuviese que proponer al Ministerio de Hacienda la forma de prestación de tales servicios siendo éste Ministerio el que finalmente decidiese sobre la propuesta formulada, previo informe preceptivo de la correspondiente Comunidad Autónoma, si ésta ejercía la tutela financiera.

Como bien se aprecia, pues, el reproche de inconstitucionalidad es sobre una cuestión bastante menor, y que, desde luego, no incide para nada en la esencia de la LRBRL, ni en los principios nucleares que la informan.

Y, sin embargo, de tan escaso basamento el Preámbulo de la Ley 3/2019, con un arrojo singular y una descarada osadía, extrae ni más ni menos la conclusión de que poco menos que tales sentencias del TC han puesto en entredicho la totalidad de las normas, principios y reglas contenidos en la LRBRL, y de ello concluye con ímpetu juvenil, con estas palabras, que cito literalmente:

"En este contexto, por tanto, la pretensión de elaborar o construir una ley integral o un marco normativo general que regule de forma holística -obsérvese la pedantería del lenguaje empleado-- todas las entidades locales de Extremadura y que actúe u opere en un marco básico estatal de régimen local ciertamente prolijo y con inevitables dudas de cuál será su destino en los próximos años, no parece una solución institucional y jurídica adecuada”. 
Y por si alguna duda quedase de tan profundo pensamiento, en el párrafo siguiente se señala:

“(...) atendiendo a las circunstancias normativas expuestas no parece muy apropiado intentar construir ese marco jurídico autonómico sobre unas bases estatales que, tras los recientes cambios normativos y la jurisprudencia constitucional citada sobre ellos, no tiene un asentamiento lo suficientemente sólido como para ofrecer soporte a un sistema normativo local extremeño que tenga vocación de permanencia en el tiempo".

Lo que se ha querido, en definitiva, es que la Ley 3/2019 no acate las bases estatales, las contenidas en la LRBRL.

En su lugar, y así se explicita también en referido Preámbulo, lo que se hace es elaborar por la Asamblea de Extremadura una nueva ley -mucho más precisa, se apunta, con evidente triunfalismo- que se encargue de recoger y contemplar un sistema de garantías de la autonomía municipal y, particularmente, de tasar un elenco de materias y funciones de competencia municipal propia que definan los contornos precisos de un modelo altamente avanzado de regulación del gobierno local.

Reténgase esta expresión de "gobierno local”, sobre la que luego volveré, ya que la misma no es inocente ni inocua, ya que es la que sirve de fundamento último al contenido de esta Ley 3/2019.

Y esa intención se plasma luego, con toda evidencia y claridad, en el capítulo I del título III de dicha Ley 3/2019, dedicado a las "Competencias municipales”, conformado por los arts. 10 a 17 , en los que, ni por asomo, se hace referencia alguna a las bases estatales recogidas en la LRBRL, de la que explícitamente se huye, señalándose, de manera expresa, que las competencias propias son solo las recogidas en el art. 15 de la Ley 3/2019, más las que se atribuyan de manera complementaria por las leyes sectoriales que apruebe la Asamblea de Extremadura; extremo que se vuelve a reiterar en el art. 17 de tal Ley 3/2019. 
Y esto es un grave defecto de esta ley, y lo es porque la fijación de tales competencias, en sus aspectos básicos y esenciales corresponden, desde luego, al Estado, tal y como lo ha mantenido siempre el TC en todas cuantas ocasiones ha tenido que enfrentarse a esta cuestión.

A este respecto, antes de analizar este problema concreto, hay que señalar que ya desde la temprana STC 4/1981, de 2 de febrero, se señaló, con carácter general, y como aviso de cara al futuro, que la autonomía hace referencia a un poder limitado. En efecto, autonomía no es soberanía -y aún este poder tiene sus límites-, y dado que cada organización territorial dotada de autonomía es una parte del todo, en ningún caso el principio de autonomía puede oponerse al de unidad, sino que es precisamente dentro de éste donde alcanza su verdadero sentido, como expresa el art. 2 de la Constitución (CE).

Y se precisó que es la ley la que concreta el principio de autonomía de cada tipo de Entes, de acuerdo con la CE; y que ésta contempla la necesidad --como una consecuencia del principio de unidad y de la supremacía del interés de la nación-- de que el Estado quede colocado en una posición de superioridad, tal y como establecen diversos preceptos de la CE, tanto en relación a las Comunidades Autónomas (CCAA), concebidas como Entes dotadas de autonomía cualitativamente superior a la administrativa (arts. 150.3 y 155, entre otros), como a los Entes locales (art. 148.1, $2^{\circ}$ ).

Entrando ya en el específico alcance de las "bases" recogidas en la LRBRL, ya la doctrina, en términos generales, había señalado, en relación con el concepto de "bases" de una Ley estatal, que por tales han de entenderse los principios normativos generales que informan u ordenan una determinada materia, constituyendo, en definitiva, el marco o denominador común de necesaria vigencia en el territorio nacional. Lo básico es, de esta forma, lo esencial, lo nuclear, o lo imprescindible de una materia, en aras de una unidad mínima de posiciones jurídicas. 
$\mathrm{Y}$ tal criterio doctrinal se ha refrendado, sin duda alguna, por el TC, como paso a exponer. Así, ya en la STC 32/1981, de 28 de julio, el TC constriñó el ámbito de actuación de las CCAA al marco que estableciese la legislación básica del Estado, que en aquellos momentos aun no existía, ya que la LRBRL es del año 1985 .

En esta sentencia se puso de relieve que corresponde al Estado la fijación de principios o criterios básicos en materia de organización y competencia de general aplicación en todo el Estado, y que cuando se trata de legislar sobre cuestiones que conciernen directamente a la composición, estructura y competencias de los entes territoriales y de sus órganos de gobierno y administración, deben las CCAA respetar las bases establecidas por la legislación vigente.

Y de ello se concluyó declarando, en lo que ahora nos afecta, que como titulares de un derecho a la autonomía constitucionalmente garantizada, las Corporaciones locales (CCLL) no pueden ser dejadas en lo que toca a la definición de sus competencias y la configuración de sus órganos de gobierno a la interpretación que cada Comunidad Autónoma pueda hacer de ese derecho.

Esto no impide, precisó el TC, que las CCAA no puedan legislar sobre la esfera local, o específicamente, municipal. Claro que pueden hacerlo; pero, eso sí, respetando las bases fijadas por el Estado.

Así lo había señalado la doctrina, cuando había puesto de relieve que el Estado no puede, en el ejercicio de una competencia básica, agotar la regulación de la materia, sino que debe dejar un margen normativo propio a la Comunidad Autónoma; y así lo declaró también esta STC 32/1981, cuando afirmó que en el respeto de esas condiciones básicas las CCAA pueden legislar, toda vez que la fijación de estas condiciones básicas no puede implicar en ningún caso el establecimiento de un régimen uniforme para todas las entidades locales de todo el Estado, sino que debe permitir opciones diversas, ya que la potestad normativa de las CCAA no es, en estos supuestos, de carácter reglamentario. 
Esta doctrina se reiteró en la STC 1/1982, de 28 de enero, al declararse en ella que lo que la $\mathrm{CE}$ persigue al conferir a los órganos generales del Estado la competencia exclusiva para establecer las bases de la ordenación de una materia determinada es que tales bases tengan una regulación normativa uniforme y de vigencia en toda la Nación, con lo cual se asegura en aras de intereses generales superiores a los de cada Comunidad Autónoma, un común denominador normativo, a partir del cual cada Comunidad, en defensa del propio interés general, podrá establecer las peculiaridades que le convengan dentro del marco de competencias que la CE y su Estatuto le hayan atribuido sobre aquella misma materia.

En la misma línea, en las SSTC 25/1983 de 7 abril y 76/1983, de 5 de agosto, se declaró que las competencias de las CCLL no pueden quedar a merced de la interpretación que cada Comunidad Autónoma haga del derecho a la autonomía local, pues tal autonomía viene exigida por el modelo de Estado que la Constitución configura.

En las posteriores SSTC 27/1987, de 27 de febrero, y 99/1987, de 11 de junio, se afirmó que debe ser el legislador estatal, con carácter general y para todo tipo de materias, el que fije unos principios o bases relativos a los aspectos institucionales (organizativos y funcionales) y a las competencias locales, encontrando cobertura a esa encomienda estatal en el concepto mismo de «bases del régimen jurídico de las Administraciones Públicas» (art. 149.1.18 CE), por cuanto dicha expresión engloba a las Administraciones Locales.

Esta doctrina se reiteró en otras sentencias, entre ellas la 48/1988, de 22 de marzo, 109/1998, de 21 de mayo, 213/1988, de 11 de noviembre, 259/1988, de 22 de diciembre, 214/1989, de 21 de diciembre, 385/1993, de 23 de diciembre, 11/1999, de 11 de febrero, y 159/2001, de 5 de julio, en las que se declaró que mediante la LRBRL el legislador estatal había ejercitado la competencia que le atribuye dicho art. 149.1.18 de la CE, estableciendo a tal propósito unas bases del régimen jurídico de la Administración Local, de aplicación directa en todo el territorio nacional, 
bases que sirven, precisamente, para la determinación concreta del régimen local autónomo.

Estas sentencias son, pues, muy claras: la "determinación concreta del régimen local autónomo" viene establecido por las bases aprobadas por el Estado, y por lo tanto el margen de maniobra que las CCAA tienen será, en exclusiva, para desarrollar las mismas.

Con ello, en suma, el TC ha dicho que las CCAA no pueden interpretar libremente la definición de las competencias y la configuración de los órganos de gobierno de las CCLL, sino que, fijados los principios básicos por parte del Estado, a ellas les corresponde, en uso de su potestad legislativa, regular sobre régimen local; pero, eso sí, respetando mencionadas bases.

En suma, como ha escrito De Diego Gómez, el TC constriñe el ámbito de actuación de las CCAA al marco que establezca la legislación básica del Estado.

Esta doctrina se ha mantenido en su integridad en más recientes pronunciamientos del TC, recogidos, entre otras, en sus sentencias 240/2006, de 20 de julio, 31/2010, de 28 de junio -en la que se declaró que el sistema establecido consiste en confiar al Estado central el establecimiento de normas legales básicas y haciendo posible que las CCAA desarrollen legislativamente dichas bases y sean titulares de las correspondientes potestades de reglamentación y ejecución de la legalidad desarrollada, siendo evidente que el papel constitucionalmente atribuido a las CCAA en cuanto a su competencia legislativa en materia de régimen local es el de desarrollo y el de ejecución de la legalidad desarrollada en el marco y competencia que sobre las bases de la misma le corresponde al Estado--, y 103/2013, de 25 de abril, en la que se señaló que las competencias autonómicas en materia de régimen local tienen que serlo de desarrollo de las bases estatales, que tienen, en primer lugar, el cometido de concretar la autonomía local constitucionalmente garantizada para establecer el marco definitorio del autogobierno de los entes locales 
directamente regulados por la Constitución, y, en segundo término, de concretar los restantes aspectos del régimen jurídico básico de todos los entes locales que son, en definitiva, Administraciones públicas.

Todo está, pues, muy claro. Según el TC, siempre existe una preeminencia de las bases estatales sobre la normativa autonómica dirigida a regular las competencias de las CCLL.

No obstante, debemos preguntarnos si tan concluyente doctrina ha sufrido algún cambio, habida cuenta de lo que se afirma en el Preámbulo de la Ley 3/2019. Y la respuesta es que no.

Si nos detenemos en las sentencias del TC expresamente invocadas en el Preámbulo de dicha Ley 3/2019, que, al parecer son las que deben conducir al olvido, y a la inaplicación, de la LRBRL, las conclusiones son idénticas, en su totalidad, a las hasta aquí expuestas.

Así, en la STC 41/2016, de 3 de marzo, al resolver la impugnación dirigida contra el régimen básico de las competencias municipales (arts. 7.4 y 25 de la LRBRL, en la redacción dada por la Ley 27/2013), y ante la alegación de la Asamblea de Extremadura, de que tal régimen incurriría en inconstitucionalidad por cercenar las atribuciones garantizadas a los municipios en algunos Estatutos de Autonomía, se declaró:

“(...) es verdad que, tal como destaca el recurso de inconstitucionalidad, el Estatuto de Autonomía, en tanto que «norma institucional básica» (art. 147.1 CE), puede contener las «líneas fundamentales o la regulación esencial» del régimen local en el ámbito territorial la Comunidad Autónoma. Ahora bien, también hemos dicho que esa regulación esencial vincula solo al legislador autonómico y únicamente en la medida en que no contradiga el régimen dictado en ejercicio de la competencia básica que al Estado corresponde en la materia en virtud de la reserva del art. 149.1.18 de la CE, precepto que ampara una regulación estatal básica sobre competencias locales que, en cuanto tal, está llamada a condicionar al legislador autonómico. A la hora de asignar o suprimir 
competencias locales al amparo de sus atribuciones estatutarias, la Comunidad Autónoma debe respetar las bases del régimen local.

Y precisó que una legislación estatal que pretendiera reducir la autonomía local al mínimo constitucionalmente garantizado podría ser tan básica y legítima como la que tratara de ensancharla al máximo. Ambas soluciones se corresponden con los polos dentro de los que puede moverse el legislador básico del régimen local en el marco de un sistema constitucional basado en el principio democrático (art. $1 \mathrm{CE}$ ).

Y lo mismo se afirmó, puesto que se formularon reproches y se suscitaron controversias competenciales muy similares, en las sentencias del TC 111/2016, de 9 de junio; 168/2016, de 6 de octubre -en la que se declaró que una norma estatutaria de régimen local no puede funcionar como límite al ejercicio de la competencia constitucionalmente atribuida al Estado en esta materia (art. 149.1.18 CE). No puede imposibilitar que este reforme las bases, ni suponer que las nuevas bases dejen de operar como mínimo común normativo, esto es, que sean inaplicables en una Comunidad Autónoma por virtud del Derecho local incluido en su Estatuto--; 44/2017, de 27 de abril; 45/2017, de 27 de abril; 54/2017, de 11 de mayo; 93/2017, de 6 de julio; y 101/2017, de 20 de julio, en las que se señaló, luego de manifestar que la LRBRL resulta aplicable en todas las CCAA, y la legislación autonómica sobre régimen local habrá de ajustarse a ella, que las normas sobre autonomía local que, eventualmente, establezca un Estatuto de Autonomía no vinculan al legislador básico; vinculan exclusivamente al legislador autonómico y solo en la medida en que sean compatibles con la ordenación básica que al Estado compete.

Así se pronunció, igualmente, la STC 107/2017, de 21 de septiembre, mediante la que se resolvió el primer conflicto en defensa de la autonomía local formulado respecto de las bases del régimen local y de la legislación estatal sobre haciendas locales, y en la que se declaró extinguida, por pérdida sobrevenida de objeto, la impugnación del art. 26.2 de la 
LRBRL, en la redacción dada por la Ley 27/2013; y se desestimó el conflicto en defensa de la autonomía local en todo lo demás.

Y también, por si aún quedase alguna duda, en la STC 180/2016, de 20 de octubre, que versó sobre un conflicto particular que se había suscitado sobre la legislación foral navarra, se declaró la plena aplicación incluso a este supuesto de la LRBRL, si bien en este caso ello es así por la expresa invocación que a este respecto se realizó tanto por la disposición adicional tercera de la LRBRL, como por la disposición adicional segunda de la citada Ley 27/2013, de racionalización y sostenibilidad de la Administración local.

De todo ello se extrae, en suma, la conclusión de que la legislación autonómica sobre el régimen local debe respetar las bases estatales, además de también, como es obvio, aunque esto por otros motivos, los principios de estabilidad presupuestaria, sostenibilidad financiera y racionalización de las estructuras administrativas, sin que quepa ningún subterfugio, ni razón de índole alguna, para no hacerlo.

Y una precisión última a este respecto. El TC no es claro respecto a la cuestión de si la LRBRL debe incluirse, o no, en el bloque de la constitucionalidad, ya que ha mantenido a este respecto posturas discrepantes.

Así, mientras que en la STC 159/2001, de 5 de julio, remitiéndose a sus sentencias 27/1987, de 27 de febrero, 109/1998, de 26 de mayo, y 259/1988, de 22 de diciembre, declaró que la LRBRL es una ley que, por definir o delimitar las competencias estatales y autonómicas, y por actuar los valores superiores consagrados en el art. 137 de la CE "tiene una singular y específica naturaleza y posición en el Ordenamiento jurídico”, integrándose sin dificultad, en aquella parte que sea concreción de principios constitucionales, dentro del llamado "bloque de la constitucionalidad" (art. 28.1 LOTC).

En la STC 240/2006, de 20 de julio, por el contrario, se negó tal tesis, al declararse en ella que la legislación básica sobre régimen local no se 
integra en el "bloque de la constitucionalidad", ni constituye canon de validez respecto de otras Leyes estatales.

Sea como fuere, esta cuestión no desmerece, en absoluto, la importancia que tiene la LRBRL; ya que como se indica en esta misma STC 240/2006 es el legislador estatal, con carácter general y para todo tipo de materias, el que tiene que fijar unos principios o bases relativos a los aspectos institucionales (organizativos y funcionales) y a las competencias locales, con cobertura en el art. 149.1.18 de la CE.

En definitiva, y como afirmación final conclusiva, es evidente e incontestable que las CCAA tienen que respetar lo dispuesto en la LRBRL, forme parte, o no, la misma del bloque de la constitucionalidad.

Pues bien, nada de esto, nada de tan clara y reiterada doctrina del TC, parece haberle importado lo más mínimo al redactor, o redactores, del Preámbulo de la Ley 3/2019, toda vez que éste, como ya indiqué, afirma, con el mayor descaro y sin el más mínimo rubor, que no parece muy apropiado intentar construir el marco jurídico autonómico sobre unas bases estatales.

Esto no es sino una evidente no toma en consideración de la reiterada, y consolidada, doctrina del TC, que si se ha hecho por desconocimiento tendría que conllevar, por incompetencia, el inmediato apartamiento de quien ha redactado citado Preámbulo de cualquier futura actividad relacionada con la esfera o la actividad normativa; y si se ha hecho a propósito, y así lo creo, sería un desacato, y como tal tiene que merecer el más contundente rechazo.

$¿$ ¿Debe deducirse de esto que la Ley 3/2019, o, por lo menos, los preceptos de la misma dedicados a establecer las competencias municipales, son inconstitucionales?

La respuesta es que no necesariamente tiene que ser así, y ello se basa en que -aunque es cierto que la falta de cualquier alusión a las bases estatales recogidas en la LRBRL, desconociéndolas y relegándolas al 
olvido, se sigue manteniendo en el texto de la Ley 3/2019, no solo, pues, en su Preámbulo- tal falta de mención a dichas bases no puede suponer, en ningún caso, que las mismas no se apliquen.

A este respecto, ya en la STC 31/2010, de 28 de junio, dictada a propósito del recurso de inconstitucionalidad planteado contra la reforma del Estatuto de Autonomía de Cataluña de 2006, se declaró de forma concluyente que la falta de referencia a las bases estatales, o, más amplia y genéricamente, a la competencia estatal ex art. 149.1.18 de la CE, no puede impedir de ninguna manera el ejercicio de esa competencia estatal.

¿Y de dónde surge, en qué se fundamenta, este, entiendo que voluntario, desconocimiento de la potestad estatal sobre el régimen local, y de las bases de la LRBRL, en esta Ley 3/2019?

Para responder a ello es el momento de ocuparme de una cuestión que al inicio dejé sin tratar, posponiéndola para un posterior momento, y que era la referida a la noción de gobierno municipal, interpretada ésta en clave de autonomía política, que entiendo que es el punto de partida de los desatinos que se han cometido en esta Ley 3/2019.

Vayamos por partes. En el Preámbulo de esta ley -tengo de nuevo que acudir a él- una vez que ha puesto de relieve, de forma totalmente incorrecta por lo ya dicho, que no es pertinente seguir los dictados de las bases estatales, se tiene que buscar un anclaje a la Ley 3/2019, y éste lo halla en el art. 55 del Estatuto de Autonomía de Extremadura (EAEx), que es, en sus propias palabras, el mejor apoyo de tal Ley 3/2019, precisando a este respecto que "es en ese marco estatutario, y particularmente en la regulación establecida en el art. 55 (del EAEx), donde se encuentra el punto de arranque del contenido de la presente ley".

Nada tendría que reprochar a estas palabras si se hubiese interpretado correctamente lo que dice este art. 55 del EAEX; pero mucho que 
objetar, sin embargo, a la interpretación que de este precepto estatutario se hace.

Y esto es así porque de dicho art. 55 se extrae la conclusión de que la ley de mayoría absoluta que en él se contiene es la única habilitada para el establecimiento de las competencias municipales. Esta interpretación es claramente errónea, y lo es tanto porque no se aplica el contenido íntegro de lo que dice este art. 55 del EAEx, como porque no se efectúa una interpretación sistemática de este precepto con el resto de los que integran el título IV de dicho Estatuto.

Es cierto que este art. 55 dice que una ley de la Asamblea aprobada por mayoría absoluta establecerá las materias y funciones de competencia autonómica susceptibles de ser gestionadas por los municipios y, en su caso, el elenco mínimo de facultades o atribuciones que sobre las mismas han de tener los ayuntamientos; pero también indica que ello es así dentro del marco normativo general, lo que ahora, en la Ley 3/2019, se olvida, desconociendo las exigencias que de ello se derivan.

Y en cuanto a la falta de interpretación sistemática, hay que señalar que en el art. 53.2 del EAEx se manifiesta que la Comunidad Autónoma regulará el régimen jurídico de las entidades locales de Extremadura, teniendo en consideración las diferentes características de las mismas y su diversa capacidad de gestión competencial; pero, todo ello, en el marco de la legislación básica del Estado, marco éste que en el ámbito de la Ley 3/2019 se encuentra "donde habita el olvido", por usar la poética frase del maestro Joaquín Sabina.

Lo que dice el EAEx en estos arts. 53 y 55 es correcto. La Comunidad de Extremadura tiene, evidentemente, capacidad para legislar en materia de régimen local; pero, eso sí, siempre teniendo presente que la legislación que ella dicte debe serlo dentro del marco normativo general conformado por la legislación básica del Estado. 
Este proceder, como acertadamente ha resaltado Álvarez García, es plenamente conforme con la doctrina del TC, según la que, recordemos, lo que la $\mathrm{CE}$ persigue al conferir a los órganos generales del Estado la competencia exclusiva para establecer las bases de la ordenación de una materia determinada es que tales bases tengan una regulación normativa uniforme y de vigencia en toda la Nación, con lo cual se asegura en aras de intereses generales superiores a los de cada Comunidad Autónoma, un común denominador normativo, a partir del cual cada Comunidad, en defensa del propio interés general, podrá establecer las peculiaridades que le convengan, dentro del marco de competencias que la CE y su Estatuto le hayan atribuido sobre aquella misma materia.

Sin embargo, en el Preámbulo de la Ley 3/2019, para que la misma no se vea constreñida por el necesario acatamiento a las bases de régimen local dictadas por el Estado, se da un salto sin red -sobre la guía, eso sí, de lo que ya habían apuntado, aun sin directamente afirmarlo, los nuevos Estatutos de Cataluña y Andalucía--, poniéndose el énfasis en otro precepto del EAEx, concretamente, en su art. 54.1, en el que se habla -incidentalmente, porque de ello no extrae ninguna conclusión relevante- de la autonomía política de los municipios.

Sin embargo, el Preámbulo de la Ley 3/2019 sí que extrae importantes conclusiones de ello. Nada menos -aunque no se diga abiertamentela de que al ser política tal autonomía, y no solo administrativa, es inaplicable el art. 149.1.18 de la CE, que se refiere, como ya se ha reiterado, a las «bases del régimen jurídico de las Administraciones Públicas».

La tesis que se sigue es, pues, la sustentada por determinados autores, tales como, por ej., Caamaño Domínguez, Font i Llovet y Velasco Caballero, quienes, partiendo de la premisa de que la autonomía local es expresión de una verdadera autonomía política, y no meramente administrativa, han señalado que las bases del régimen jurídico de las Administraciones públicas del art. 149.1.18 de la CE no dan cobertura a la pretensión de la regulación del Gobierno local o ni siquiera del régimen local, 
ya que sólo ampararían a una regulación de las bases de la Administración local entendida de una forma reductora; excluyendo todo aquello que pueda tener que ver con la idea de Gobierno local, que, a su juicio, se presentaría como materia no incluida en el art. 149 de la CE.

Como bien ha escrito De La Quadra-Salcedo Fernández del Castillo, de esta afirmación, que parte de la premisa de que son dos cosas diferentes la Administración y el Gobierno, se desprende que son distintas, y sin conexión entre ellas, las funciones administrativas, y el aparato que las sirve, y las funciones políticas, incardinadas en la idea de Gobierno, y de todo ello se deduciría que el art. 149.1.18 de la CE sí permitiría al Estado establecer las bases del régimen jurídico de todas las Administraciones, pero ello nada tendría que ver con la dimensión política de los Entes locales, que sería así una materia distinta, y, como tal, no prevista en dicho art. 149.1.18 de la CE.

A partir de tal razonamiento se llega a la conclusión de que el régimen local no es una materia que esté reservada al Estado en el art. 149.1 de la $\mathrm{CE}$ y, en consecuencia, se trataría el régimen local de una materia que pueden libremente, y de forma exclusiva, asumir las CCAA, sin estar constreñidas para ello por las bases del régimen jurídico de las Administraciones públicas del art. 149.1.18 de la CE.

Sin embargo, como bien apunta De La Quadra-Salcedo Fernández del Castillo, esta tesis no es convincente. El hallazgo de un título virgen en torno al concepto de "Gobierno local" que, supuestamente, quedaría fuera de las bases del art. 149.1.18 de la CE, no cuenta con argumentos suficientes que lo justifiquen; y pretender extraer del uso de ambos términos -gobierno y administración- la consecuencia de que en la CE se quiere que las bases del 149.1.18 de la CE se contraigan a una artificial diferenciación entre gobernar y administrar no es admisible, como también había puesto de relieve ya Morell Ocaña.

Como señala el propio De La Quadra-Salcedo Fernández del Castillo, la misma Constitución sitúa el art. 140 -en que se alude al «gobierno» y 
«administración» de los municipios- al comienzo del capítulo II del Título VIII, con una rúbrica del capítulo que es bien significativa («Capítulo II. De la Administración Local»), por lo que no tendría que existir duda alguna de que para la CE los municipios y provincias son, ante todo y sobre todo, Administración, y al ser ello así es claro que dentro del régimen jurídico de las Administraciones públicas se comprende también la Administración local.

Y así lo han entendido también las sucesivas sentencias del TC que se han enfrentado a la cuestión, y a las que ya me he referido precedentemente, razones todas ellas que me llevan a concluir afirmando que si la tesis de fundar una radical diferenciación de régimen jurídico en la separación entre los términos gobierno y administración fue la que se tuvo presente a la hora de redactar la Ley 3/2019, la misma es, por completo, equivocada, desacertada y errónea.

\section{LAS VAGAS Y ETÉREAS NORMAS SOBRE FINANCIACIÓN LOCAL RECOGIDAS EN LA LEY 3/2019}

Otra triunfalista afirmación que se contiene en la al parecer tan maravillosa --para quienes la han aprobado--, Ley 3/2019, es la referida a la financiación municipal.

A este respecto en el ya tan reiterado Preámbulo de la misma se señala que en relación a este aspecto esta Ley 3/2019, rompe una tradición normativa en las CCAA de régimen de financiación ordinario que consiste en regular siempre en paralelo (esto es, en normas distintas) competencias y financiación local, lo que suele ser una fuente notable de desajustes y problemas; para evitar los cuales se afirma que en este campo dicha Ley 3/2019 pretende aportar una visión holística -otra vez el término de marras--, que vaya sumando poco a poco las tres dimensiones imprescindibles de un modelo sólido de gobierno local: competencias, financiación y sistema institucional de garantías. 
La intención es muy buena. Siempre he defendido que lo mejor y más operativo es, sin duda, que el elenco de competencias de las CCLL y, singularmente, de los municipios, y la forma de financiar las mismas, vayan unidas en un único texto, habida cuenta de su clara complementariedad, ya que sin los necesarios y adecuados medios económicos difícilmente pueden atenderse, de forma satisfactoria, referidas competencias.

Pero todo ha quedado en eso, en una buena intención, puesto que al ver el articulado de la Ley 3/2009, se comprueba, otra vez más, la insoportable levedad de la misma, que no aporta nada nuevo que no conociésemos ya en relación con esta cuestión de la financiación municipal.

Dicha ley comienza limitándose a recoger, en su art. 42, una serie de principios de actuación de las haciendas locales extremeñas: autonomía financiera, estabilidad presupuestaria y sostenibilidad financiera, suficiencia financiera, solidaridad, legalidad, responsabilidad financiera, transparencia, objetividad, economía, eficiencia, control, unidad de caja y racionalidad en la gestión de sus recursos.

Pues bien, todos ellos serían igualmente aplicables existiese, o no, la Ley 3/2019, ya que el actuar de este modo es obligado por aplicación directa, entre otros preceptos, de los arts. 133, 135, 138 y 142 de la CE; 55 y 60 del EAEx; 105 y sigs. de la LRBRL, y numerosos preceptos del Texto Refundido de la Ley reguladora de las Haciendas locales (TRLRHL), aprobado por el RDLegis. 2/2004, de 5 de marzo, cuya cita sería ahora inapropiada para no agotar la paciencia del lector.

Descendiendo a más detalle, nos encontramos con que el art. 142 de la $\mathrm{CE}$ recoge las dos fuentes primordiales de financiación de los Entes locales: sus tributos propios y la participación en ingresos del Estado.

Veamos, en primer lugar, si la ley 3/2019 aporta alguna novedad en relación con los tributos propios de las CCLL radicadas en Extremadura.

Ninguna. Ni siquiera los menciona. Y no lo hace porque no puede hacerlo. 
Brevemente, hay que indicar que debido, por un lado, a la vigencia del principio de reserva de ley en el ámbito tributario (arts. 31.3 y 133.1 $\mathrm{CE}$ ), y, por otro, a que la legislación de régimen local no atribuye a las CCLL el poder de aprobar leyes, sino normas con carácter reglamentario (ordenanzas municipales), de ello se deriva que para ordenar los tributos municipales es precisa una ley, que, además, tiene que ser estatal, y no autonómica.

Esta exigencia de que dicha ley sea estatal, queda patente en, entre otras, las sentencias del TC 179/1985, de 19 de diciembre, 96/1990, de 24 de mayo; 331/1993, de 12 de noviembre; 233/1999, de 16 de diciembre; 104/200o, de 13 de abril; 13/2007, de 18 de enero, y 31/2010, de 28 de junio, en las que se ha puesto de relieve, partiendo de la exigencia recogida en los arts. 31.3 y 133.1 y 2 de la CE, que la creación de los tributos locales ha de operarse a través del legislador estatal, teniendo esta potestad su anclaje constitucional "en la competencia exclusiva sobre Hacienda General (art. 149.1.14 CE), que corresponde al Estado. Si bien, también se ha precisado por el TC, que "en virtud de la autonomía de los Entes locales constitucionalmente garantizada y del carácter representativo del Pleno de la Corporación municipal, es preciso que la ley estatal atribuya a los Acuerdos dictados por éste (los acuerdos dimanantes del ejercicio de la potestad de ordenanza), un cierto ámbito de decisión acerca de los tributos propios del Municipio" (STC 233/1999, de 16 de diciembre).

Por tanto, las posibilidades de actuación de una ley autonómica sobre el establecimiento y regulación de los tributos locales son inexistentes, y así lo ha tenido que asumir la Ley 3/2019, que nada dice, pues, de esta primera fuente de financiación de los municipios, y ello porque, repito, no puede hacerlo.

En consecuencia, esa pretendida visión holística de la Ley 3/2019 es también inexistente en relación con este aspecto del establecimiento de los tributos propios locales. 
Veamos qué sucede con la otra fuente nuclear de financiación de los entes locales, constituida según dicho art. 142 de la CE, por la participación en los tributos del Estado y de las CCAA. Es palmario que la participación de las CCLL en los tributos del Estado no puede regularse, al menos en sus aspectos sustantivos, en la Ley 3/2019.

A este respecto, cabe recordar que es doctrina reiterada del TC que la fijación de los criterios de distribución de la participación de los Entes locales en los tributos del Estado corresponde en exclusiva a éste.

Así, a título de ejemplo, en las sentencias del TC 96/1990, de 24 de mayo; 237/1992, de 15 de diciembre; 331/1993, de 12 de noviembre; 233/1999, de 16 de diciembre y 104/2000, de 13 de abril, se ha declarado que es al legislador estatal a quien incumbe dar efectividad a los principios de suficiencia de las Haciendas locales y de solidaridad y equilibrio territorial, mediante la determinación de unos criterios homogéneos y uniformes de distribución entre los distintos Entes locales de su participación en los ingresos del Estado.

De hecho, como se afirmó en la STC 150/1990, de 4 de octubre, si una ley autonómica incidiese en los criterios de participación de los municipios en los ingresos del Estado, tal ley "podría incurrir efectivamente en inconstitucionalidad, no ya por contrariar el principio de autonomía local, sino por invadir las competencias del Estado relativas a la regulación de la participación de los entes locales en los tributos estatales”.

En consecuencia, tampoco la Ley 3/2019 puede regular los aspectos sustantivos y nucleares de la participación de las CCLL en los tributos estatales.

Sin embargo, en dicha Ley sí que podría haberse hecho mención a determinadas cuestiones relacionadas con esta materia, que sería posible constitucional y legalmente regular, y, sin embargo, tampoco se ha 
hecho, poniéndose con ello de manifiesto que la pretendida visión integral de la Ley 3/2019 es un puro mito, sin base alguna.

Me refiero, en concreto, como bien ha escrito en términos generales Moreno Fernández, a que nada impide que la participación de las CCLL en los tributos estatales se hubiese articulado a través de un procedimiento en virtud del que tales ingresos se perciban por medio de la Comunidad Autónoma de Extremadura (CAEx) y que ésta, seguidamente, procediese a distribuirlos a los municipios extremeños, respetando, eso sí, los criterios de reparto establecidos por la legislación del Estado en la materia.

Este procedimiento es el que se sigue en, por ej., el art. 219.2 del Estatuto de Autonomía de Cataluña (EACat), aunque antes de él también se utilizaba en el art. 48.2 del anterior Estatuto catalán (LO 4/1979), y sobre esta forma de actuar ha declarado el TC que ello es plenamente conforme con la $\mathrm{CE}$, pues si bien es cierto, como ya he dicho, que la fijación de los criterios de distribución de la participación de los Entes locales en los tributos y subvenciones incondicionadas del Estado corresponde de forma exclusiva a éste $e x$ art. 149.1.14 a de la CE, ello no impide que, una vez fijados dichos criterios, su reparto pueda efectuarse a través de los correspondientes entes autonómicos, siempre que en esta tarea se respeten "los criterios de reparto establecidos por el Estado de los que no puede apartarse".

Así se ha declarado, entre otras, por las sentencias del TC 96/1990, de 24 de mayo; 237/1992, de 15 de diciembre; 331/1993, de 12 de noviembre; 171/1996, de 30 de octubre y 31/2010, de 28 de abril, que fue la que declaró la plena constitucionalidad en este aspecto concreto del antes mencionado art. 219.2 del EACat., recogiéndose igual tesis en las más recientes sentencias del TC 41/2016, de 3 de marzo y 78/2018 de 5 julio.

En definitiva, ni siquiera en esta cuestión menor ha innovado nada la Ley 3/2019, dando así muestras, una vez más, de su completa futilidad, y de su absoluta prescindibilidad. 
Cabe preguntarse ahora: ¿y qué ocurre con la participación de los municipios extremeños en los tributos de la CAEx?

La regulación normativa de esta cuestión sí puede realizarse por la Ley 3/2019, ya que esta forma de actuar está legitimada por la esfera de actuación política de la Junta de Extremadura (así se ha declarado por, entre otras, las sentencias del TC 84/1982, de 23 de diciembre; 31/2010, de 28 de junio y $78 / 2018$ de 5 julio), y cuenta con el respaldo de lo que establece el art. 60.2 del EAEx, que señala, a estos efectos, que una ley de la Asamblea de Extremadura, establecerá un fondo de finalidad incondicionada, dotado a partir de los ingresos tributarios de la Comunidad y que se distribuirá entre los municipios teniendo en cuenta, entre otros factores, su población, sus necesidades de gasto y su capacidad fiscal.

A este fondo es al que se refiere el art. 45 de la Ley 3/2019, en el que se señala que el mismo se establecerá en las leyes anuales de Presupuestos Generales de la CAEX, dotado con al menos 76 millones de euros, provenientes de los ingresos tributarios de la Comunidad, y que se distribuirá entre los municipios a través de una cuantía fija y otra variable, teniendo en cuenta una serie de factores, tales como, entre otros, la población, con especial atención a la población total menor de 25 años y mayor de 65 años; las necesidades de gasto; la inversa de la capacidad fiscal; la inversa de la renta per cápita, y el desempleo, remitiéndose a los trabajos que desarrolle una Comisión Mixta, integrada en el Consejo de Política Local, la concreción de los porcentajes de distribución que correspondan a cada uno de dichos factores.

No voy a entrar a examinar los factores que se citan para llevar a cabo este reparto, ni, por tanto, si los mismos son, o no, los más idóneos para la finalidad pretendida, que es, a tenor de los ya citados art. 60 del EAEx y 45 de la Ley 3/2019: intentar conseguir un equilibrio territorial y la realización efectiva del principio de solidaridad. 
Sin embargo, si apunto que, a mi juicio, la Ley 3/2019, es poco concreta: por una parte, porque los factores que cita son, entre otros, dejando, pues, la puerta abierta a la introducción de nuevos criterios de reparto, y, por otra, porque tampoco especifica los porcentajes que se aplicarán a cada uno de tales factores, los cuales también se remiten a un órgano que funciona extramuros de la Asamblea de Extremadura, lo cual, desde luego, significa hurtar poder de decisión al poder legislativo, lo cual, en mi opinión, no debe merecer más que críticas.

Esta falta de regulación integral por parte de la Ley 3/2019 vuelve a poner de relieve que la pretensión holística de dicha Ley es pura fachada, y lo es también porque no veo razón alguna para que citada Ley no haya ido mucho más lejos de lo que lo ha hecho en otros dos específicos aspectos, que tienen que ver con la participación de los municipios en los ingresos tributarios de la CAEx, y que la propia Ley 3/2019 cita, pero no concreta ni, desde luego, desarrolla.

El primero de ellos aparece mencionado en el art. 11 de la Ley $3 / 2019$, en el que se indica que la ley podrá atribuir ámbitos materiales específicos o determinadas funciones o facultades de las competencias municipales a la ciudad de Mérida en su condición de capital de la Comunidad Autónoma, de acuerdo con lo establecido en la Ley 7/2015, de 31 de marzo, así como a las capitales de provincia (Badajoz y Cáceres) o en relación con aquellos municipios que, atendiendo a su peso demográfico o especial capacidad de gestión, puedan asumir eficientemente la prestación de determinados servicios públicos en el ámbito municipal.

Y se añade que tales atribuciones de ámbitos materiales específicos aplicables a determinados municipios vendrán acompañadas, en todo caso, de la suficiencia financiera requerida para su correcto ejercicio, lo que se reitera en el art. 17.2 de la propia Ley 3/2019.

Esta importante cuestión de la atribución de nuevas y mayores funciones y facultades a los municipios reseñados queda diferida a lo que establezcan leyes futuras, y esto no es necesariamente criticable, puesto 
que a medida que vayan apreciándose nuevas necesidades es cuando es pertinente que se doten a los municipios, en los que tales necesidades se aprecien, de las correspondientes funciones y facultades.

Con todo, si considero que es un desacierto de la Ley 3/2019 el no haber establecido ya un mecanismo de financiación, con visos de estabilidad y permanencia, para salvaguardar las necesidades financieras de los municipios afectados por ese haz de posibles nuevas funciones y facultades, toda vez que parece evidente que si esto existiese ello sería un incentivo, un estímulo, para que tales municipios decidiesen asumir las mismas, incrementando de esta suerte su autonomía municipal, lo cual, quizá no se produzca con el sistema establecido, en el que la suficiencia financiera se fía íntegramente a que así se establezca en esas leyes futuras. ¿Y si las mismas no garantizan dicha suficiencia? Si no es así, es palmario que la autonomía municipal sufrirá, ya que los municipios que podrían desarrollar nuevas y más amplias funciones y facultades se abstendrán de proponerlas ante la carencia de medios económicos para afrontarlas.

Para solventar este problema, bien podría haberse creado a través de esta Ley 3/2019 otro nuevo fondo -en este caso condicionado- que se nutriese de ingresos tributarios de la CAEx - o, si se quiere, por distinguirlo aún más del fondo incondicionado que se contempla en los arts. 60.2 del EAEx y 45 de la Ley 3/2019, que estuviese dotado en exclusiva de las correspondientes cesiones de los porcentajes que se estableciesen de cada uno de los ingresos tributarios recaudados de los tributos propios de la CAEx - que sólo se destinaría a cubrir, a medida que ello se fuese produciendo, las mayores necesidades de financiación de los municipios a los que se refiere el antes mencionado art. 11 de la Ley 3/2019, cuando éstos fuesen implantando las nuevas funciones o facultades en relación con sus competencias municipales aludidas en referido precepto -por ello sería un fondo condicionado--, que ya conocerían de antemano que cuando decidiesen dar este paso iban a contar, sin tener que estar al albur de que otra ley así lo estableciese, con la suficiencia financiera necesaria para el correcto ejercicio de tales nuevas funciones o facultades. 
Este proceder también encajaría en este tema que vengo analizando de la participación de los municipios extremeños en los tributos de la CAEx, si bien el sistema ya no sería único, como ahora ocurre, sino que tendría naturaleza dual. Esto no plantea problema jurídico alguno.

Sería sencillamente seguir la estela, adaptándola a otros fines diferentes, de lo dispuesto en el régimen normativo de la participación de los municipios en los tributos del Estado (PTE), que aparece actualmente regulada en los arts. $111 \mathrm{y}$ ss. del TRLRHL, que tiene, precisamente, como bien señala Arrieta Martínez de Pisón, esta naturaleza dual, ya que en este sistema PTE a los municipios que sean capitales de provincia o Comunidad autónoma o que tengan una población igual o superior a 75.0oo habitantes, se conforma con dos magnitudes diferentes, pues aparte de permitirles obtener medios económicos del que allí se denomina Fondo Complementario de Financiación, se les ceden también determinados porcentajes de los rendimientos que no hayan sido cedidos a las CCAA, en el IRPF, en el IVA, y en los IIEE de fabricación; cesión ésta que, por el contrario, no está contemplada para los restantes municipios que no reúnan las condiciones señaladas, puesto que respecto a ellos, sólo se prevé la participación en tributos del Estado en función de tres variables: población (75\%), esfuerzo fiscal $(12,5 \%)$ y la inversa de la capacidad tributaria (12,5\%), sin que en ningún caso se establezca la posibilidad de ceder a los mismos una parte del rendimiento de los impuestos del Estado.

Y pasando a la segunda de las cuestiones antes mencionadas que bien debieran haberse tratado por esta Ley 3/2019, hay que señalar que este nuevo fondo condicionado cuya creación apunto en los párrafos precedentes podría aprovecharse también para intentar alcanzar otro importante objetivo, que la Ley 3/2019 apunta, pero no desarrolla, y que está íntimamente relacionado con la realidad demográfica del municipalismo extremeño. 
A este respecto, en el Preámbulo de dicha Ley 3/2019 se señala, simplemente, que éste tiene ante sí importantes retos "que difícilmente podrá asumir por sí solo, tales como el envejecimiento de la población y el despoblamiento rural", para afrontar lo cual "se requerirá, tal vez, plantear más tarde o más temprano estrategias de redefinición de la planta municipal”, las cuales pospone, sin embargo, para un largo e inconcreto futuro, para "un interin temporal que puede ser extenso", en sus propias palabras.

Considero, y así lo he expuesto en diversas ocasiones, que la cuestión del inframunicipalismo es muy grave en España --y, particularmente en algunas CCAA como, por ej., la nuestra--, que no ha seguido en esta materia los posicionamientos, a veces radicales; pero siempre coherentes $\mathrm{y}$, a mi juicio, acertados, aplicados en otros países próximos a nosotros.

Por ello estimo, que esta cuestión sí tendría que haberse analizado con seriedad y rigor en esta Ley 3/2019, que, sin embargo, una vez más calla sobre los asuntos verdaderamente transcendentes, y ello pese a que a la Junta de Extremadura ya se le dijo en la STC 41/2016, de 3 de marzo --con doctrina que ha sido reiterada en la más reciente STC 101/2017, de 20 de julio--, que: "El procedimiento de fusión de municipios es un contenido típico de la materia «régimen local» cuya regulación corresponde a las CCAA en el marco de las coordenadas básicas que establezca el Estado ex art. 149.1.18 CE”.

Ningún problema, pues, habría existido -todo lo contrario--, para que la Ley 3/2019 hubiese sido beligerante en este crucial asunto, y hubiese empezado a poner las primeras piedras para intentar resolver este muy grave problema, cuyas consecuencias futuras son impredecibles. Nada de nada otra vez más.

Una posible primera medida que se podría implantar, desde ya mismo, para paliar al menos este problema -resolverlo definitivamente requeriría, como es obvio, adoptar medidas de más enjundia y mayor calado- bien podría ser la de utilizar este fondo condicionado al que me 
vengo refiriendo para incentivar las fusiones municipales, de forma que aquellos municipios que decidiesen llevar a término de forma voluntaria estas fusiones recibiesen unas determinadas cantidades de citado fondo, de las que no disfrutarían aquellos otros que se mostrasen renuentes y remisos a emprender esta necesaria, y yo diría que imprescindible, tarea.

\section{A MODO DE CONCLUSIÓN}

Por todo lo expuesto, la Ley 3/2019 me parece decepcionante, e imbuida de un falso triunfalismo, pues poco menos que parece que es ella la que ha creado, y la única que defiende a la autonomía municipal, siendo así que esto no se aprecia en modo alguno de la lectura de los preceptos que en ella se contienen, y tampoco es, desde luego, una ley integral y global reguladora y defensora de dicha autonomía municipal.

Lo que sí es holística esta Ley --mejor dicho, habría que decir "casi”, pues siempre cabe esperar alguna mente iluminada que contribuya a que los desatinos se acumulen y crezcan- es en relación con la incontinente vocación que tiene a la hora de crear órganos.

Los mismos, y seguro que alguno me he quedado sin controlar, son los siguientes:

El Consejo de Política Local de Extremadura (el COPLE), que funciona en Pleno y en Comisiones Sectoriales, y que está conformado por 23 vocales, y 3 personas más: la persona titular de la Consejería con competencias en materia de Administración Local o, en su caso, la persona titular de la Vicepresidencia; la persona titular de la Presidencia de la Federación de Municipios y Provincia de Extremadura (FEMPEX); y el secretario o secretaria.

La Comisión de Garantías de la Autonomía Local, compuesta de un total de 15 miembros, y que se estructura en 2 órganos: el Pleno y la Presidencia. 
La Comisión Bilateral, que se constituye cuando no se acepten, en todo o en parte, las propuestas de reforma o modificación formuladas por la Comisión de Garantías de la Autonomía Local a los anteproyectos de ley o de decreto legislativo y a los proyectos de reglamento que afecten a la autonomía local; y que se integran 3 miembros de la Consejería promotora de la iniciativa normativa, y otros 3 miembros de dicha Comisión de Garantías de la Autonomía Local.

La Comisión de Conciliación, de composición paritaria entre representantes de la CAEx y de los entes locales, encargada de llevar a efecto los actos de conciliación de los conflictos que puedan haber surgido entre la Junta de Extremadura y los entes locales enfrentados.

La Comisión Mixta formada por representantes de la Junta de Extremadura y por los de los municipios extremeños, encargada de determinar los factores de distribución del fondo de financiación incondicionado del art. 45 de la Ley 3/2019.

La Comisión de estudio y propuesta, encargada de analizar la cartera de servicios sociales y los impactos financieros que para las haciendas municipales tiene la gestión de dichos servicios.

Y la Comisión de estudio, que tiene el cometido de elaborar un informe sobre la adecuación de la legislación sectorial a las previsiones recogidas en el art. 15 de la Ley 3/2019. No está nada mal, tratándose de una sola Ley. 


\section{REFERENCIAS BIBLIOGRÁFICAS}

Álvarez García, Vicente. Cinco estudios sobre el nuevo Estatuto de Autonomía de Extremadura, Madrid: Ed. Iustel, 2012.

Arrieta Martínez de Pisón, Juan. "La participación de los Municipios en los tributos del Estado (II)”. En Los Tributos Locales, coordinado por Marín-Barnuevo Fabo, 977-1011. Cizur Menor, Madrid: Thomson-Civitas, 2011.

Caamaño Domínguez, F. (2003): “Autonomía local y Constitución. Razones para recuperar la causalidad perdida”. En Anuario del Gobierno Local 2003. La Ley de Modernización del Gobierno Local. Cooperación intermunicipal, dirigida por T. Font i Llovet, 47-69. Barcelona, Madrid: Fundación Democracia y Gobierno Local, Institut de Dret Públic, 2004.

-. "Autonomía local y Constitución. Dos propuestas para otro viaje por el callejón del gato”, Revista Española de Derecho Constitucional 70 (2004): 161-188.

Cano Bueso, Juan. "Problemas constitucionales que condicionan la calidad de las normas”, Revista española de la función consultiva 6 (2006): 121-130

De Diego Gómez, A. (2014): "Las competencias municipales en la Ley 27/2013, de 27 de diciembre, de Racionalización y Sostenibilidad de la Administración Local, con especial referencia a las competencias propias”. La Administración al día, 4 de julio de 2014, http://laadministracionaldia.inap.es/noticia.asp?id=1503524.

De La Quadra-Salcedo Fernández del Castillo, Tomás. "Corporaciones locales, reforma de los Estatutos y competencias estatales”. Civitas. Revista española de Derecho Administrativo 145 (2010): 5-55. 
Fernández Rodríguez, Tomás Ramón. "De la banalidad a la incoherencia y la arbitrariedad. Una crónica sobre el proceso, al parecer imparable, de degradación de la Ley”. El Cronista del Estado Social y Democrático de Derecho o (2008): 46-55.

Font i Llovet, Tomàs. "La reconstrucción jurídica de la autonomía local: El gobierno local y la reforma de los Estatutos". Anuario del Gobierno Loca 1 (2003): 3-46.

- (2006): "El régimen local en la reforma de los Estatutos de Autonomía". En El régimen local en la reforma de los estatutos de autonomía, editado por Tomàs Font i Llovet, Luis Ignacio Ortega Álvarez y Francisco Velasco Caballero. Madrid: Centro de Estudios Políticos y Constitucionales. $\mathrm{M}^{\mathrm{o}}$ de la Presidencia, 2006.

Martín Moreno, José Luis. "Función consultiva en los procedimientos de creación del Derecho. Pérdida de oportunidad y daño moral”, Revista española de la función consultiva 7 (2007): 99-111.

Morell Ocaña, Luis. El régimen local español, Tomo I, Madrid: Ed. Civitas, 1988.

Moreno Fernández, Juan Ignacio. "El Estatuto de Autonomía de Cataluña y su frustrado "modelo diferencial” de financiación”, Iustel, Revista General de Derecho Constitucional 13 (2011). https://www.iustel.com/v2/revistas/detalle_revista.asp?id_noticia $=411060$

Muñoz Machado, Santiago. "Las deformaciones del ordenamiento jurídico y la aplicación de las Leyes en el nuevo sistema constitucional”, Documentación administrativa 200 (1984): 43-73. Ver también en Cinco estudios sobre el poder y la técnica de legislar. Madrid: Civitas, 1986.

Velasco Caballero, Francisco. "Autonomía local y subsidiariedad en la reforma de los estatutos de autonomía", Anuario del Gobierno Local. 20041 (2005): 117-160 
Tajadura Tejada, Javier. (2006): "Concepto y valor de los Preámbulos de las leyes”, La Ley 3 (2006): 1886-1889.

Clemente Juan Checa González Área de Derecho Financiero y Tributario Departamento de Derecho Público Universidad de Extremadura Av. Universidad, $\mathrm{s} / \mathrm{n}$ 10003 Cáceres (España) ccheca@unex.es https://orcid.org/oooo-0002-3042-618X 